\title{
Low frequency oscillation characteristics of East China Power Grid after commissioning of Huai-Hu ultra-high voltage alternating current project
}

\author{
Chao WANG ( $\bowtie)$, Yang LV, Hongyang HUANG, \\ Jing ZHANG, Jihong LI, Yingyi LI, \\ Weizhen SUN, Yong CHANG
}

\begin{abstract}
The low frequency oscillation characteristics of East China Power Grid after commissioning of the first ultra-high voltage alternating current (UHVAC) projectthe Huai-Hu UHVAC project are studied. Several low frequency oscillation cases occurred in East China Power Grid in the past few years are reviewed and summarized. Based on the analysis of the different typical operation modes, the main low frequency oscillation modes in East China Power Grid in the early stages of development of ultra-high voltage (UHV) are summarized, and the impacts of the significant power grid maintenance on low frequency oscillation characteristics are analyzed. Besides, the oscillation mode of UHV generators to East China Power Grid is researched, and the importance of the power system stabilizator (PSS) is emphasized. Furthermore, the comparative analysis between the time domain and the frequency domain is carried out, and the influences of the governing system on low frequency oscillation characteristics are revealed. Finally, both the focus and the direction of low frequency oscillation research are presented.
\end{abstract}

Keywords Ultra-high voltage (UHV), Low frequency oscillation, Forced oscillation, Power system stabilizator (PSS), Governing system

CrossCheck date: 29 January 2015

Received: 4 June 2014/ Accepted: 29 January 2015 / Published online: 23 July 2015

(C) The Author(s) 2015. This article is published with open access at Springerlink.com

C. WANG, H. HUANG, J. ZHANG, J. LI, Y. LI, W. SUN, State Grid Zhejiang Electric Power Company, Hangzhou 310007,

China

$(\bowtie)$ e-mail: wangchao@zju.edu.cn

Y. LV, State Grid Jilin Electric Power Company, Changchun 130000, China

Y. CHANG, State Grid Operation Company, Beijing 100052, China

\section{Introduction}

With the continuous expansion of power grid and the increasing of power transmission, low frequency oscillation has become an important problem in power system operation [1-3]. At the end of 2013, the first $1000 \mathrm{kV}$ ultrahigh voltage alternating current (UHVAC) project (Huai$\mathrm{Hu}$ UHVAC Project) in East China Power Grid was put into operation. After this, some other UHVAC and ultrahigh voltage direct current (UHVDC) projects, such as BinJin UHVDC project, Zhe-Fu UHVAC project, and NingShao UHVDC project will be put into operation one by one. Due to these ultra-high voltage (UHV) projects, the stability characteristics of East China Power Grid will change greatly and the problem of low frequency oscillation will be prominent. Thus, the research on low frequency oscillation of East China Power Grid is of high engineering value.

Previous researches have been carried out on the theories of low frequency oscillation, including the negative damping theory [4], the forced power oscillation theory [5, 6] and the parametric resonance theory [7], etc.

In recent years, low frequency oscillation caused by negative damping has been monitored in East China Power Grid several times. For example, the oscillation between power grid of Zhejiang and Fujian Provinces, whose frequency is $0.3-0.4 \mathrm{~Hz}$, is shown in Fig. 1. Another example is the negative damping oscillation occurred in $500 \mathrm{kV}$ Shenglong Power Plant with $2 \times 1000 \mathrm{MW}$ units, which is weakly connected to Zhejiang power grid. In early years when the power system stabilizators (PSSs) of Shenglong power units had yet not been put into operation, low frequency oscillation between Shenglong Power Plant and Zhejiang power grid had occurred several times, as shown in Fig. 2. This oscillation mode has been suppressed effectively after commissioning of the PSSs. 


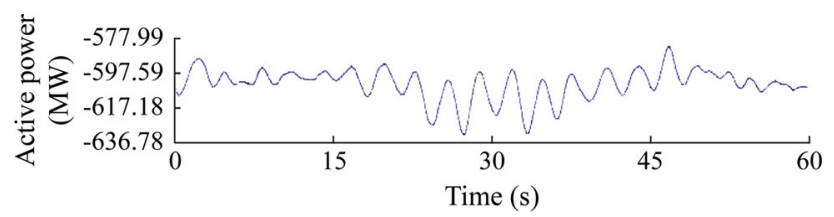

Fig. 1 Power oscillation curve of connection lines between Zhejiang and Fujian Provinces (wide area measurement system (WAMS) data)

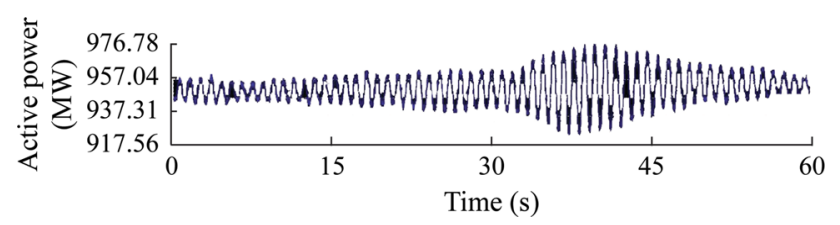

Fig. 2 Power oscillation curves of units in Shenglong Power Plant (WAMS data)

The forced power oscillation theory gives a good explanation on the power oscillation of Qinshan nuclear generator occurred in October, 2012. $1 \mathrm{~Hz}$ oscillation occurred in a 300 MW nuclear unit in Qinshan Plant several times. The maximum power amplitude is about $20 \mathrm{MW}$, and the longest oscillation duration is about 37 minutes. It is nearly a zero-attenuation oscillation mode, as shown in Fig. 3. It is concluded that this is a forced oscillation in the end. The reason is that the direct drive valve (DDV) (a device in governor) of a small power unit in $110 \mathrm{kV}$ power grid is not stable at certain load level, thus it excites the load fluctuation of the small unit and finally leads to the forced oscillation around $1 \mathrm{~Hz}$ in many power units nearby, including the Qinshan nuclear unit. This problem is now solved by the replacement of the defective DDV of the small unit.

The parametric resonance theory has not been verified in East China Power Grid, but the parametric resonance due to improper parameter of DC modulators has been observed in China Southern Power Grid in 2007 [8]. Except for these three theories, other theories, such as bifurcation theory and chaotic oscillation theory are also mentioned, yet haven't been proved in practical engineering so far.

\section{Research objects and methods}

In this paper, the network of East China Power Grid is studied as the research subjects, and the research time period is during the year 2013-2014. The reason is that during this period, the first UHVAC was put into operation, while the second UHVAC project has not. In the early stages of development of UHV power grid, especially when there was only one UHVAC project, the power grid is relatively weak, and the problem of low frequency oscillation is more prominent. Problems during this period

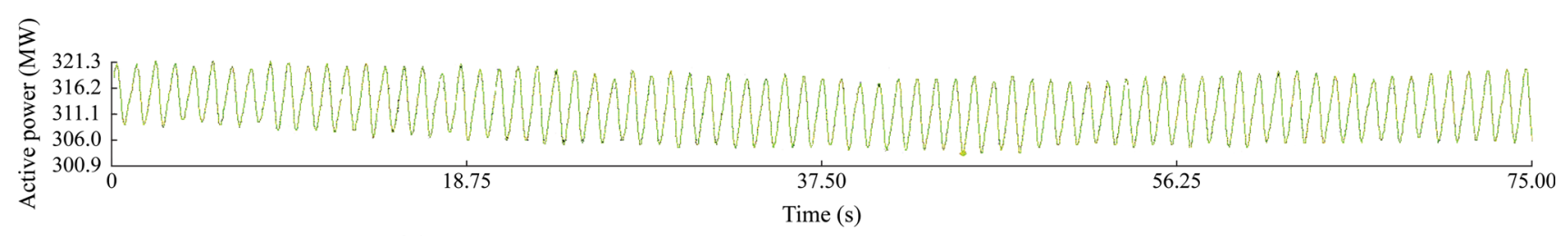

(a) Active power curve of $20 \mathrm{kV}$ generating unit (No. 1) of Zhejiang Jiaxing Power Plant

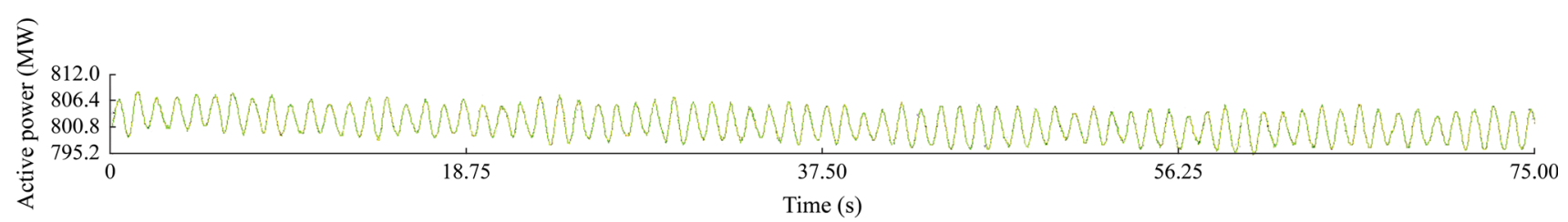

(b) Active power curve of $18 \mathrm{kV}$ generating unit (No. 7) of Zhejiang Jiaxing No. 2 Power Plant

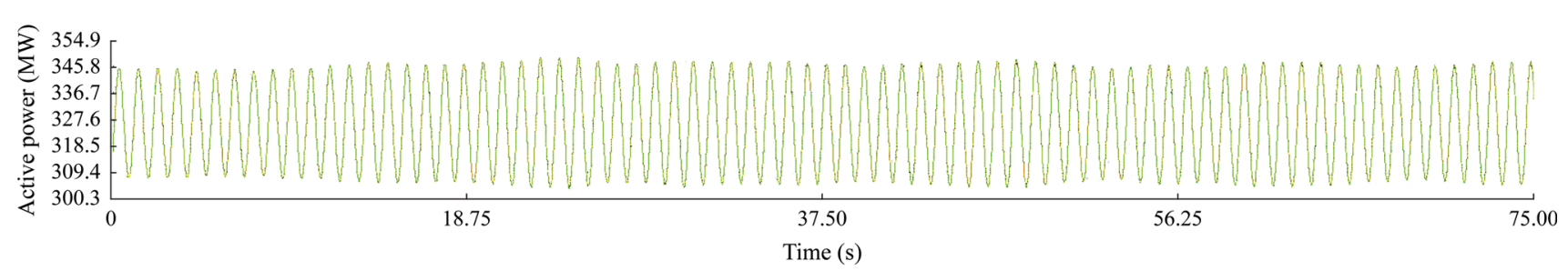

(c) Active power curve of $18 \mathrm{kV}$ generating unit (No. 1) of Zhejiang Qinshan Power Plant

Fig. 3 Power oscillation curves of Qinshan nuclear power generating unit and some other units nearby 
are considered to be more representative, and research results will be more valuable for other power companies who plan to develop UHV.

The Huai-Hu UHVAC project, which is connected to Anhui, Zhejiang and Shanghai Provinces, is the first $1000 \mathrm{kV}$ UHVAC demonstration project in East China Power Grid. It has $2 \times 653 \mathrm{~km}$ transmission lines on the same tower. The generators of Pingwei and Yuanzhuang Power Plants were accessed into the UHVAC project gradually. The geographical schematic diagram and the distribution of main generator group of East China Power Grid in 2013-2014 are shown in Fig. 4.

The main generators are simulated by the sub-transient model considering the damping windings. Most of the generators connected to the $500 \mathrm{kV}$ system in East China Power Grid use the self-excited static excitation system with the PSS module. The models of the excitation system and the PSS are established based on the actual measurement. The static load models are used, and the frequency effect coefficient of the load is ignored except for the generators in Fujian Province.

Nowadays, low frequency oscillation analytical methods include the time domain method and frequency domain method. These two kinds of methods are used in different cases according to different research targets and characteristics. Implicitly Restarted Arnoldi Algorithm [9] is a widely-used eigenvalue-analytical method with some certain advantages in practical analysis of large-scale power systems and has been integrated into the Power System Department-Bonneville Power Administration (PSD-BPA) business program. Therefore, the research in this paper is carried out based on the method.

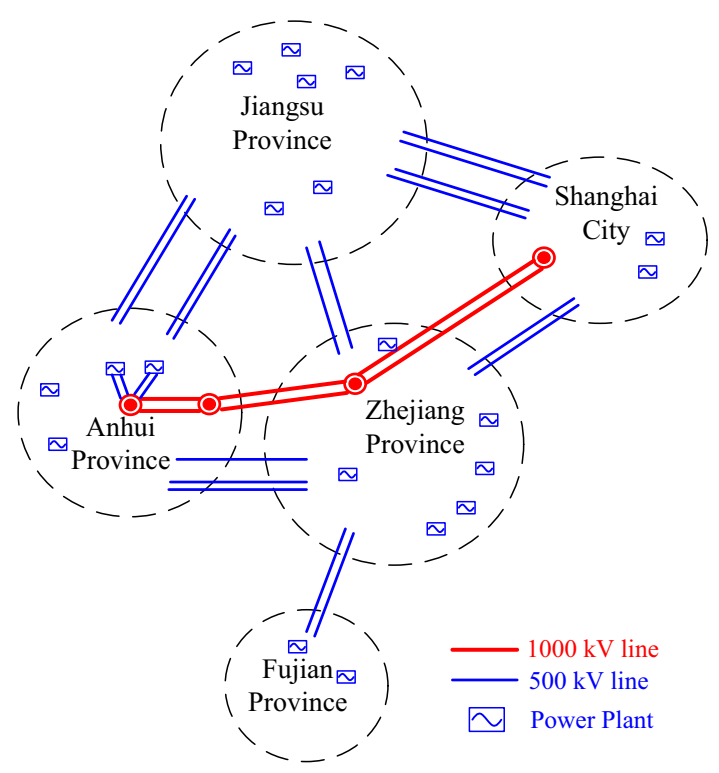

Fig. 4 Geographical schematic diagram and distribution of main generator group of East China Power Grid in 2013-2014

\section{Results and analysis}

\subsection{Main oscillation modes of East China Power Grid}

After commissioning of Huai-Hu UHVAC Project, the main oscillation modes of East China Power Grid are listed.

\subsubsection{Oscillation mode between Fujian Province and East China}

In this mode, the generators in Fujian Province oscillate against the main network of East China Power Grid. The oscillation frequency is $0.31 \mathrm{~Hz}$ and the damping ratio is $19.37 \%$. The modal distribution is shown in Fig. 5. If the PSS of Fujian generators is out of service, the oscillation frequency will increase to $0.34 \mathrm{~Hz}$, while the damping ratio drop to $5.72 \%$, thus it proves the good inhibitory effect of the PSS of Fujian generators on this oscillation mode.

\subsubsection{Oscillation mode between Anhui Province and East China}

In this mode, the generators in Anhui Province oscillate against the main network of East China Power Grid. The oscillation frequency is $0.63 \mathrm{~Hz}$ and the damping ratio is $5.46 \%$, as shown in Fig. 6. The mode is of high risk if the PSS of Anhui units is out of service. In this case, the oscillation frequency increases to $0.65 \mathrm{~Hz}$, while the damping ratio drops to $0.36 \%$, which is very close to zero damping.

\subsubsection{Oscillation mode between Yangcheng Power Plant and East China}

In this mode, the generators in Yangcheng, which is a very large and important power plant in East China,

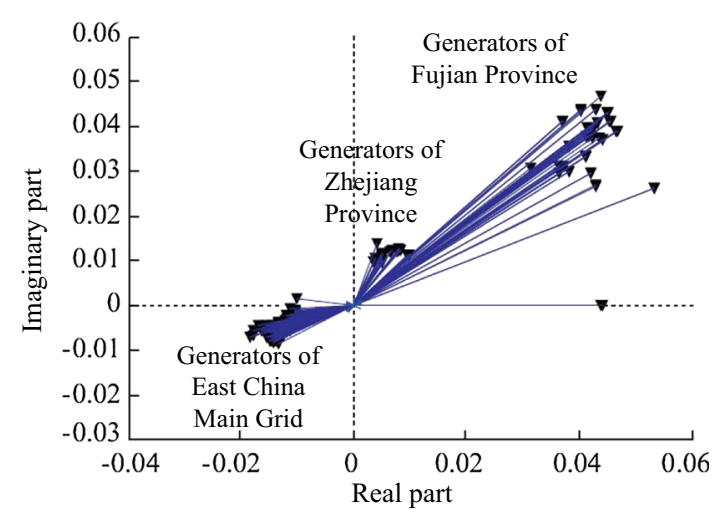

Fig. 5 Modal distribution of low-frequency oscillation mode between Fujian Province and East China 


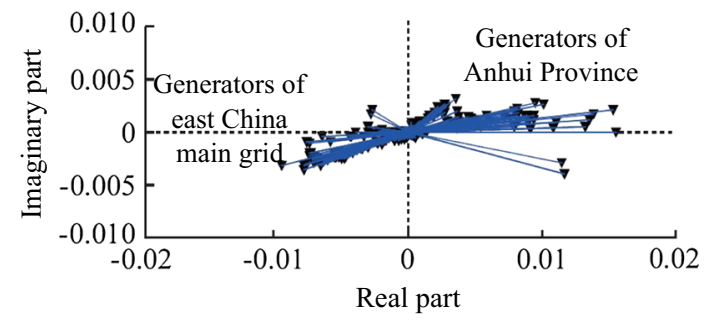

Fig. 6 Modal distribution of low-frequency oscillation mode between Anhui Province and East China

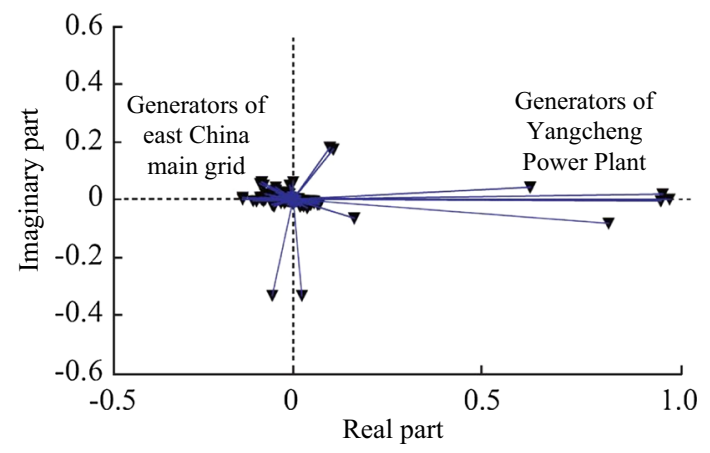

Fig. 7 Modal distribution of low-frequency oscillation mode between Yangcheng Power Plant and East China

oscillate against the main network of East China Power Grid. The oscillation frequency is $0.72 \mathrm{~Hz}$, and the damping ratio is $10.72 \%$, as shown in Fig. 7. If the PSS of Yangcheng units is out of service, the oscillation will be negatively damped (the damping ratio is $-1.84 \%$ ), which will be a serious threat to the operation of East China Power Grid. Thus it proves the vital role of the PSS of Yangcheng generators in the depression of the oscillation mode.

\subsubsection{Oscillation mode between Zhejiang Province and East China}

As the power load in Southern Zhejiang Province increases continuously and no big power plant has been put into operation in Southern Zhejiang Province during recent years, there is less demand for the long-distance power transmission from Southern Zhejiang Province. Therefore, the oscillation mode between Zhejiang Province and East China Power Grid, which used to be weakly damped, is no longer acute. In 2014, the oscillation frequency is $0.93 \mathrm{~Hz}$, and the damping ratio is $9.40 \%$, as shown in Fig. 8. Most of the generators connected to $500 \mathrm{kV}$ systems in Zhejiang Province participate in the oscillation mode. As is seen in Fig. 8, the generators in Northern Zhejiang Province swing against those in Southern Zhejiang Province in the mode. If the PSS of Zhejiang units is out of service, the oscillation frequency will increase to $0.98 \mathrm{~Hz}$, while the damping ratio drops to $7.09 \%$.

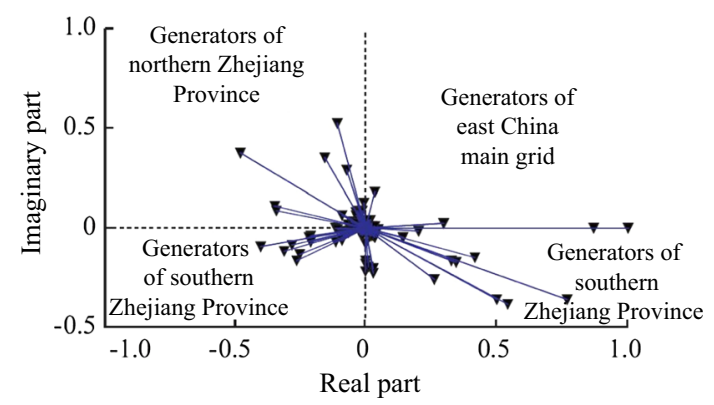

Fig. 8 Modal distribution map of low-frequency oscillation mode between Zhejiang Province and East China

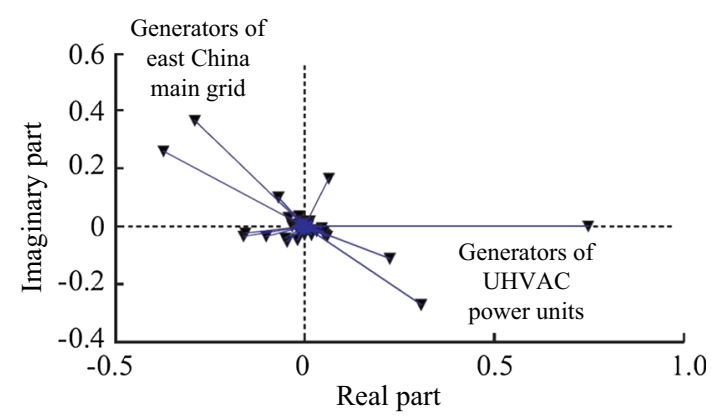

Fig. 9 Modal distribution of low-frequency oscillation mode between UHV units and East China

\subsubsection{Oscillation mode between the UHV units and East China}

After commissioning of Huai-Hu UHVAC project, the power of Yuanzhuang and Pingwei Power Plants is transmitted to East China via the UHVAC lines, thus forming a point-to-grid oscillation mode. In the mode, the UHV units oscillate relative to the East China Power Grid. The oscillation frequency is $1.07 \mathrm{~Hz}$, and the damping ratio is $18.29 \%$, as shown in Fig. 9. If the PSS of UHV units is out of service, the oscillation frequency will increase to $1.15 \mathrm{~Hz}$, while the damping ratio drops to $-2.17 \%$.

The typical oscillation modes before commissioning of Huai-Hu UHVAC project are also calculated for comparison, as shown in Table 1. As is seen, East China power grid is significantly strengthened after commissioning of HuaiHu UHVAC project. As a result, the frequencies of the main oscillation modes increase in different degrees, and the main East China power grid shows good damping characteristics.

\subsection{Analysis on typical oscillation modes in different power operation modes}

Low frequency oscillation modes in 6 different power operation modes of East China Power Grid are analyzed, and the detailed results are shown in Table 2. Considering 
the successive commissioning of UHV units in 2013-2014, the oscillation characteristics of UHV units vary in different stages. Special research on oscillation modes of UHV units in different operation modes is carried out, as shown in Table 3.

The main conclusions are as follows:

1) In 6 typical operation modes, the main oscillation modes include the oscillation among Fujian Province and East China, Anhui and East China, Yangcheng Power Plant and East China. As the demand of long-distance and large power transmission from Southern Zhejiang Province decreases in recent years, the weakly damped oscillation between Southern Zhejiang Province and East China is no longer acute. After commissioning of Huai-Hu UHVAC project, the power of Yuanzhuang and Pingwei Power Plants is transmitted via UHVAC to East China. A new oscillation mode between the UHV power plant and East China appears. The damping ratios of these oscillation

Table 1 Low frequency oscillation mode of East China power grid before/after commissioning of Huai-Hu UHVAC project

\begin{tabular}{llllll}
\hline Oscillation mode & \multicolumn{2}{l}{ Before } & & \multicolumn{2}{l}{ After } \\
\cline { 2 - 3 } \cline { 5 - 6 } & Fequency $(\mathrm{Hz})$ & Damping ratio $(\%)$ & & Frequency (Hz) & Damping ratio $(\%)$ \\
\hline Fujian Province to east China & 0.29 & 18.74 & 0.31 & 19.37 \\
Anhui Province to east China & 0.63 & 5.34 & 0.63 & 5.46 \\
Yangcheng Power Plant to east China & 0.28 & 12.12 & 0.72 & 10.72 \\
Zhejiang Province to east China & 0.53 & 7.63 & 0.93 & 9.4 \\
UHV units to east China & - & - & 1.07 & 18.29 \\
\hline
\end{tabular}

Table 2 Low frequency oscillation mode of East China in different typical operation modes of power grid

\begin{tabular}{|c|c|c|c|}
\hline Operation mode & $\begin{array}{l}\text { Damping ratio } \\
(\%)\end{array}$ & $\begin{array}{l}\text { Oscillation frequency } \\
(\mathrm{Hz})\end{array}$ & Oscillation mode \\
\hline \multirow[t]{4}{*}{ Peak-load of 2013 summer } & 11.78 & 0.7119 & Yangcheng Power Plant to East China \\
\hline & 18.28 & 0.2864 & Fujian Province to East China \\
\hline & 7.67 & 0.6139 & Anhui Province to East China \\
\hline & 11.08 & 0.9265 & Zhejiang Province to East China \\
\hline \multirow[t]{4}{*}{ Intermediate-load of 2013 summer } & 10.28 & 0.7096 & Yangcheng Power Plant to East China \\
\hline & 19.82 & 0.2892 & Fujian Province to East China \\
\hline & 6.19 & 0.6294 & Anhui Province to East China \\
\hline & 9.60 & 0.9483 & Zhejiang Province to East China \\
\hline \multirow[t]{4}{*}{ Valley-load of 2013 summer } & 13.39 & 0.7475 & Yangcheng Power Plant to East China \\
\hline & 18.83 & 0.3257 & Fujian Province to East China \\
\hline & 9.04 & 0.6590 & Anhui Province to East China \\
\hline & 11.87 & 1.0087 & Zhejiang Province to East China \\
\hline \multirow[t]{5}{*}{ Peak-load of 2013 winter } & 10.81 & 0.7159 & Yangcheng Power Plant to East China \\
\hline & 22.49 & 0.2888 & Fujian Province to East China \\
\hline & 5.65 & 0.6285 & Anhui Province to East China \\
\hline & 9.40 & 0.9332 & Zhejiang Province to East China \\
\hline & 18.29 & 1.0737 & UHV units to East China \\
\hline \multirow[t]{5}{*}{ Intermediate-load of 2013 winter } & 9.59 & 0.7188 & Yangcheng Power Plant to East China \\
\hline & 22.54 & 0.2986 & Fujian Province to East China \\
\hline & 4.31 & 0.6366 & Anhui Province to East China \\
\hline & 8.87 & 0.9591 & Zhejiang Province to East China \\
\hline & 17.91 & 1.0786 & UHV units to East China \\
\hline \multirow[t]{5}{*}{ Valley-load of 2013 winter } & 10.19 & 0.7389 & Yangcheng Power Plant to East China \\
\hline & 21.43 & 0.3322 & Fujian Province to East China \\
\hline & 7.93 & 0.6707 & Anhui Province to East China \\
\hline & 9.92 & 0.9624 & Zhejiang Province to East China \\
\hline & 22.13 & 1.0914 & UHV units to East China \\
\hline
\end{tabular}


Table 3 Low frequency oscillation modes between UHV units and East China in the different stages

\begin{tabular}{|c|c|c|c|c|c|c|}
\hline \multirow{2}{*}{$\begin{array}{l}\text { Mode } \\
\text { Number }\end{array}$} & \multirow[t]{2}{*}{ Operation mode } & \multirow{2}{*}{$\begin{array}{l}\text { Units (rated } \\
\text { output) }\end{array}$} & \multicolumn{2}{|l|}{ With PSS } & \multicolumn{2}{|c|}{ Without PSS } \\
\hline & & & $\begin{array}{l}\text { Frequency } \\
(\mathrm{Hz})\end{array}$ & $\begin{array}{l}\text { Damping ratio } \\
(\%)\end{array}$ & $\begin{array}{l}\text { Frequency } \\
(\mathrm{Hz})\end{array}$ & $\begin{array}{l}\text { Damping ratio } \\
(\%)\end{array}$ \\
\hline 1 & Peak-load of 2013 winter & 4 units (2540 MW) & 1.0737 & 18.29 & 1.1519 & -2.17 \\
\hline 2 & Valley-load of 2013 winter & 4 units (2000 MW) & 1.0222 & 16.28 & 1.1826 & 2.04 \\
\hline 3 & Peak-load of 2014 summer & 7 units (4860 MW) & 0.9069 & 7.08 & 0.9412 & -6.73 \\
\hline 4 & $\begin{array}{l}\text { Valley-load of } 2014 \\
\text { summer }\end{array}$ & 7 units (3800 MW) & 0.9971 & 12.45 & 1.0013 & -0.98 \\
\hline 5 & Peak-load of 2014 winter & 8 units (5860 MW) & 0.7489 & 9.98 & 0.8636 & -6.74 \\
\hline 6 & Valley-load of 2014 winter & 8 units (4600 MW) & 0.9095 & 10.34 & 0.9400 & -0.61 \\
\hline
\end{tabular}

modes are all above 3\% when the PSSs of UHV units are put into service. (In China, it is generally considered that the damping ratio should be above $3 \%$ in order to ensure the dynamic stability of power system). If the corresponding PSS is out of service, the damping ratios of all these modes will decrease greatly and some may even drop to negative values. Therefore, it is very important to assure that the PSSs of generators are in service so as to enhance the dynamic stability of the power system.

2) In 2014, a large capacity of generators in Northern Anhui Province are put into operation gradually. When a large amount of power is transmitted from Northern Anhui Province to Southern Anhui Province, the damping ratio of Anhui Province to East China oscillation mode decreases significantly. For example, in intermediate-load operating mode in winter, the damping ratio is $4.31 \%$, which is quite close to $3 \%$. In practical operation, it must pay attention to dynamic stability analysis on the power system when some important equipment is out of service.

3) In 2013 summer, the frequencies of all the oscillation modes are less than those in 2013 winter. The explanation is that the network structure is continually strengthened after commissioning of power system projects including the $1000 \mathrm{kV}$ UHVAC project.

4) The research on the oscillation modes of the UHV units shows that the damping ratio decreases continually while the capacity of UHV units increases. If the PSSs of UHV units are out of service, the damping ratios of the low frequency oscillation in the typical operation modes in 2013 and 2014 will be far below 3\%, which means that there will be a high risk of low frequency oscillation in practical operation. When the PSSs of UHV units are in operation, all the damping ratios will be above $5 \%$.

\subsection{Influences of important equipment maintenance} on low frequency oscillation characteristics

The influences of important equipment maintenance on the low frequency oscillation mode of East China Power Grid are researched. Six important equipment maintenance projects in 2013 winter are selected as the research ones, which include the Huainan-Wuhu $1000 \mathrm{kV}$ UHVAC single line maintenance (Mode 1), the Wuhu-Anji $1000 \mathrm{kV}$ UHVAC single line maintenance (Mode 2), the Wuhu-Anji $1000 \mathrm{kV}$ UHVAC double line maintenance (Mode 3), the Ningshuang-5906 (500 kV inter-provincial contact line of Zhejiang and Fujian Province) single line maintenance (Mode 4), the Jingping-5901 (500 kV inter-provincial contact line of Zhejiang and Anhui Provinces) single line maintenance (Mode 5) and the Qiaoyong-5493 (500 kV important transmission channel across the Qiantang River) single line maintenance (Mode 6). The results are listed in Table 4.

The main conclusions are as follows:

1) In normal mode, when the PSSs of UHV units are all in service, the oscillation between UHV units and East China can be inhibited efficiently. However, in the UHV line maintenance mode (Modes 1,2 and 3), the damping ratio cannot meet the requirement. More research on optimizing the PSS parameters of UHV units needs to be done. As the UHV lines are connected to the provincial power grids, the UHV line maintenance has influences not only on the oscillation mode between UHV units and East China, but also on the oscillation mode between provincial power grids.

2) In 2013-2014, there is only one double $500 \mathrm{kV}$ lines connecting Fujian Province to East China. The problem of the low frequency oscillation is acute in the tie-line maintenance mode, which decreases the oscillation frequency greatly (Mode 4). Therefore, the ties between Fujian Province and East China are advised to be further strengthened. Besides, as the network of East China and the network structures between provincial power grids are compact, the influences of maintenance on oscillation mode will not be too large (Modes 5 and 6) in most cases.

\subsection{Time-domain simulation and verification}

The time-domain simulation after disturbance is carried out and simulation results are compared with that of the 
Table 4 Low frequency oscillation mode of East China power grid in important maintenance modes

\begin{tabular}{|c|c|c|c|c|c|c|c|c|c|c|}
\hline \multirow[t]{2}{*}{$\begin{array}{l}\text { Oscillation } \\
\text { mode }\end{array}$} & \multicolumn{2}{|c|}{$\begin{array}{l}\text { Fujian Province to } \\
\text { east China }\end{array}$} & \multicolumn{2}{|c|}{$\begin{array}{l}\text { Anhui Province to } \\
\text { east China }\end{array}$} & \multicolumn{2}{|c|}{$\begin{array}{l}\text { Yangcheng power } \\
\text { plant to east China }\end{array}$} & \multicolumn{2}{|c|}{$\begin{array}{l}\text { Zhejiang Province } \\
\text { to east China }\end{array}$} & \multicolumn{2}{|c|}{$\begin{array}{l}\text { UHV units } \\
\text { to east China }\end{array}$} \\
\hline & $\begin{array}{l}\text { Frequency } \\
(\mathrm{Hz})\end{array}$ & $\begin{array}{l}\text { Damping } \\
\text { ratio }(\%)\end{array}$ & $\begin{array}{l}\text { Frequency } \\
(\mathrm{Hz})\end{array}$ & $\begin{array}{l}\text { Damping } \\
\text { ratio }(\%)\end{array}$ & $\begin{array}{l}\text { Frequency } \\
(\mathrm{Hz})\end{array}$ & $\begin{array}{l}\text { Damping } \\
\text { ratio }(\%)\end{array}$ & $\begin{array}{l}\text { Frequency } \\
(\mathrm{Hz})\end{array}$ & $\begin{array}{l}\text { Damping } \\
\text { ratio }(\%)\end{array}$ & $\begin{array}{l}\text { Frequency } \\
(\mathrm{Hz})\end{array}$ & $\begin{array}{l}\text { Damping } \\
\text { ratio }(\%)\end{array}$ \\
\hline Mode 1 & 0.294 & 23.67 & 0.6289 & 5.52 & 0.7162 & 10.7 & 0.9535 & 8.72 & 1.0039 & 13 \\
\hline Mode 2 & 0.294 & 23.64 & 0.6275 & 5.48 & 0.7165 & 10.77 & 0.9327 & 9.47 & 1.0487 & 16.22 \\
\hline Mode 3 & 0.292 & 23.02 & 0.598 & 4.39 & 0.7131 & 11.23 & 0.9312 & 9.64 & 1.0893 & 4.94 \\
\hline Mode 4 & 0.2391 & 24.38 & 0.6219 & 5.22 & 0.716 & 10.82 & 0.9327 & 9.37 & 1.0683 & 18.38 \\
\hline Mode 5 & 0.2937 & 23.61 & 0.6216 & 5.41 & 0.7153 & 10.79 & 0.9325 & 9.48 & 1.0683 & 16.86 \\
\hline Mode 6 & 0.2924 & 23.55 & 0.6272 & 5.51 & 0.715 & 10.85 & 0.9404 & 9.58 & 1.0716 & 17.11 \\
\hline $\begin{array}{c}\text { Normal } \\
\text { mode }\end{array}$ & 0.2888 & 22.49 & 0.6285 & 5.65 & 0.7159 & 10.81 & 0.9332 & 9.4 & 1.0737 & 18.29 \\
\hline
\end{tabular}

frequency-domain study. The oscillation mode between UHV units and East China has been selected as the research subjects. A three-phase permanent fault occurs in the UHV Huainan station busbar and $0.1 \mathrm{~s}$ later the threephase switch trips. The active power curve of UHV line after this disturbance is shown in Fig. 10.

The Prony-analysis of the active power curve is carried out based on a "moving-window algorithm" [10]. In this case, the length of each data window is set to $2.5 \mathrm{~s}$, while each data window has a time interval of $1 \mathrm{~s}$, and the analysis region is $0.5-5 \mathrm{~s}$. The Prony-analysis result is shown in Table 5.

Based on Table 5, the parameters of the oscillation mode between UHV units and East China Power Grid can be obtained, as shown in Table 6 .

The results between time and frequency domain shows that the results of this two methods are basically consistent. In the Prony-analysis method, the parameter setting of the data windows has a large influence on the analysis results. Combined engineering experience, we suggest that the best analysis region may be the 2 nd to the 5 th cycles of the oscillation curve after the disturbance. Similar conclusions can be obtained based on research on other oscillation modes.

\subsection{Analysis on the influence of governing system on low frequency oscillation characteristics}

In practical engineering nowadays, the research on low frequency oscillation mainly focuses on excitation system, while the influence of governing system is rarely considered. In order to investigate the influence of governing system on low frequency oscillation, the oscillation mode between UHV units and East China power grid is selected as the research object. Figure 11 shows the active power curve of UHV line after the disturbance with/without governing system.

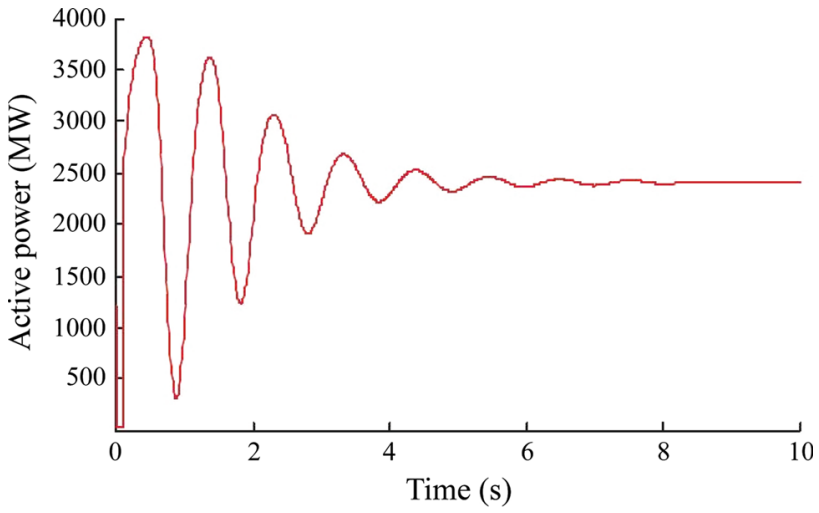

Fig. 10 Active power curve of UHV line after disturbance

Table 5 Prony-analysis results of system signal after disturbance

\begin{tabular}{lll}
\hline Data window & Frequency $(\mathrm{Hz})$ & Damping ratio $(\%)$ \\
\hline 1 & 1.1005 & 11.53 \\
2 & 1.0958 & 12.21 \\
3 & 1.1264 & 15.60 \\
4 & 0.9894 & 14.56 \\
5 & 1.0819 & 16.35 \\
6 & 0.9058 & 18.69 \\
\hline
\end{tabular}

Table 6 Results between time domain method and frequency domain method

\begin{tabular}{lll}
\hline Method & $\begin{array}{l}\text { Oscillation } \\
\text { frequency (Hz) }\end{array}$ & $\begin{array}{l}\text { Damping } \\
\text { ratio (\%) }\end{array}$ \\
\hline $\begin{array}{l}\text { Prony-anlysis (time-domain) } \\
\begin{array}{l}\text { Eigenvalue analysis } \\
\text { (frequency-domain) }\end{array}\end{array}$ & $\begin{array}{l}1.0500 \\
1.0737\end{array}$ & 14.82 \\
Relative error (\%) & 2.20 & 18.29 \\
\hline
\end{tabular}

As is seen from Fig. 11, there are some differences between the active power curves of UHV units after the disturbance with or without governing system. In order to 


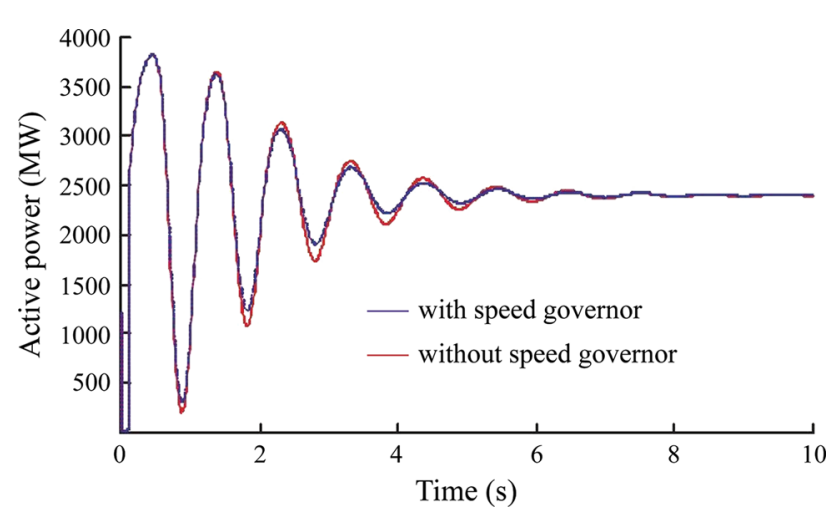

Fig. 11 Active power curve of UHV after disturbance with/without governing system

Table 7 Low frequency oscillation modes between UHV units and East China under different conditions

\begin{tabular}{lll}
\hline Operating condition & $\begin{array}{l}\text { Oscillation } \\
\text { frequency (Hz) }\end{array}$ & $\begin{array}{l}\text { Damping } \\
\text { ratio (\%) }\end{array}$ \\
\hline $\begin{array}{l}\text { UHV units with governing } \\
\text { system and PSS }\end{array}$ & 1.0737 & 18.29 \\
$\begin{array}{l}\text { UHV units with PSS (without } \\
\text { governing system) }\end{array}$ & 1.0745 & 17.19 \\
$\begin{array}{l}\text { UHV units with governing } \\
\text { system (withous PSS) }\end{array}$ & 1.1519 & -2.17 \\
\hline
\end{tabular}

illustrate the problem more clearly, the frequency-domain analysis on the low frequency oscillation modes between UHV units and East China are carried out, as shown in Table 7.

As we can see form Table 7, the governing system has some influence on low frequency oscillation characteristic, but not as large as the excitation system (PSS). We can also see from the simulation results that the governing system can improve the system damping to a certain degree. Generally speaking, the response of governing system is much slower than that of the excitation system, thus their responding frequency bands are different. When the oscillation frequency is larger than $1 \mathrm{~Hz}$, the excitation system plays a major role while the effect of governing system is not obvious. However, with the continuous construction of UHV and continued expansion of large-scale power grid, operating conditions of long distance and large capacity power transmission may occur, the oscillations with very low frequencies may be excited, thus the effect of governing system will be more obvious and should not be neglected.

\section{Conclusion}

The main low frequency oscillation characteristics of East China Power Grid after commissioning of Huai-Hu
UHVAC project are researched. The main conclusions are as follows.

1) After commissioning of Huai-Hu UHV project, the typical oscillation modes mainly include the oscillation among Fujian Province and East China, Anhui Province and East China, Yangcheng Power Plant and East China. As the demand of long-distance power transmission from Southern Zhejiang Province drops, the oscillation mode between Zhejiang Province and East China Power Grid, which used to be a weakly damped mode, is improved. A new oscillation mode between UHV units and East China appears. It is very important to ensure the PSS of UHV units to be in service, and the optimization of PSS parameters of UHV units needs to be done continuously.

2) The influences of the important equipment maintenance on low frequency oscillation characteristics of East China Power Grid are researched. It is proved that the maintenance in regional area will not have great influence on power grid stability. But in some regions where the grid structure is not too strong (e.g., the maintenance of UHV tielines), the risk of poorly-damped low frequency oscillation may increase. Thematic analysis should be carried out combined with specific work in practical engineering.

3) The time-domain simulation after disturbance is carried out compared with the result of the frequency-domain. Combined with engineering practice, the engineering experiences of parameter setting in time-domain simulation are discussed.

4) The influence of governing system on low frequency oscillation is researched based on the time-domain as well as frequency-domain simulation. It is considered that normally the governing system has some influence on low frequency oscillation characteristic, but not as large as the excitation system (PSS). Their responding frequency bands are quite different. With the continuous expansion of power system scale, oscillations with very low frequencies may occur, which will make the effect of governing system more obvious and non-ignorable.

Open Access This article is distributed under the terms of the Creative Commons Attribution 4.0 International License (http:// creativecommons.org/licenses/by/4.0/), which permits unrestricted use, distribution, and reproduction in any medium, provided you give appropriate credit to the original author(s) and the source, provide a link to the Creative Commons license, and indicate if changes were made.

\section{References}

[1] Qiu XZ, Yu ZX, Lei M et al (2008) WAMS based statistics and assessment of low frequency oscillation in Shandong Power Grid. Automat Electr Power Syst 32(6):95-98 (in Chinese)

[2] Xue YS, Hao SP, Liu JY (2009) A review of analysis methods for low frequency oscillations. Automat Electr Power Syst 33(3):1-8 (in Chinese) 
[3] Li P, Xu GH, Liu CX et al (2010) A review of inter-area oscillations in China Southern Grid in a time-frequency perspective. Automat Electr Power Syst 34(22):18-23 (in Chinese)

[4] Demello FP, Concordia C (1969) Concepts of synchronous machine stability as affected by excitation control. IEEE Trans Power Appar Syst 88(4):316-329

[5] Tang Y (2006) Fundamental theory of forced power oscillation in power system. Power Syst Technol 30(10):29-33 (in Chinese)

[6] Yu YP, Min Y, Chen L (2009) Analysis of forced power oscillation steady-state response properties in multi-machine power systems. Automat Electr Power Syst 33(22):5-9 (in Chinese)

[7] Qi J (2009) Delays power system low frequency oscillation damping control based on wide area measurement system. $\mathrm{Ph} \mathrm{D}$ Thesis, Zhejiang University, Hangzhou, China (in Chinese)

[8] Li P, Wu XC, Zhang Y et al (2007) Interaction and coordination of modulation controllers of multi-infed HVDC in CSG. Automat Electr Power Syst 31(21):90-93 (in Chinese)

[9] Ni XS, Wang KW, Wang ZQ et al (2009) Improvement of the refined Cayley-Aronldi algorithm for computing the critical eigenvalues of power systems. Automat Electr Power Syst 33(15):13-17 (in Chinese)

[10] Ding L, Xue AC, Li J et al (2010) A moving-window Prony algorithm for power system low frequency oscillation identification. Automat Electr Power Syst 34(22):24-28 (in Chinese)

Chao WANG is a power system engineer with State Grid Zhejiang Electric Power Company, Hangzhou, China. His research interests are power system operation and control, reliability analysis, UHVDC and UHVAC.
Yang LV is a power system engineer with State Grid Jilin Electric Power Company, Changchun, China. His research interests include harmonic impedance measurement.

Hongyang HUANG is a power system engineer with State Grid Zhejiang Electric Power Company, Hangzhou, China. His research interests are power system stability and HVDC transmission.

Jing ZHANG is a power system engineer with State Grid Zhejiang Electric Power Company, Hangzhou, China. His research interests are power system stability, HVDC and FACTS, power quality and signal processing.

Jihong LI is a power system engineer with State Grid Zhejiang Electric Power Company, Hangzhou, China. His research interests include power system operation and management.

Yingyi LI is a power system engineer with State Grid Zhejiang Electric Power Company, Hangzhou, China. His research interests include power system operation and control.

Weizhen SUN is a power system engineer with State Grid Zhejiang Electric Power Company, Hangzhou, China. His research interests include power system operation and control.

Yong CHANG is a power system engineer with State Grid Operation Company, Beijing, China. His research interests are HVDC transmission and power system stability. 